\title{
ANÁLISE DENDROCRONOLÓGICA DO CRESCIMENTO DE Araucaria angustifolia (Bertol.) Kuntze NO PLANALTO SERRANO DE SANTA CATARINA
}

\author{
T. M. LOIOLA*, A. F. HESS, D. R. KLEIN, S. M. KREFTA, J. P. DALLABRIDA, A. DENEGA, B. NASCIMENTO \\ Universidade do Estado de Santa Catarina \\ tascillaloiola@gmail.com*
}

Artigo submetido em 06/08/2016 e aceito em 23/06/2019

DOI: $10.15628 /$ holos.2019.4927

\section{RESUMO}

Existe uma preocupação com a preservação do genótipo florestal das formações com a presença de Araucaria angustifolia (Bertol.) Kuntze, sendo necessária a aquisição de informações, como dados sobre o crescimento, incremento e idade das árvores, que possam ser utilizadas em planos de manejo sustentável. Assim, o objetivo deste estudo foi realizar um diagnóstico dendrocronológico do crescimento diamétrico acumulado para a compreensão da sua variabilidade, com a intenção de auxiliar nas ações de manejo da espécie. Para tanto, a partir da análise dos anéis de crescimento, foram utilizadas informações dendrocronológicas de 133 árvores, abordadas de maneira individual em fragmentos naturais, localizados no município de São Joaquim. Os resultados demonstraram que, nesses fragmentos, a espécie apresenta incremento em diâmetro variando entre 0,20 e 1,42 cm.ano-1, e idade variando de 16 a mais de 100 anos. Nos sítios estudados, ocorre uma redução gradativa do crescimento em diâmetro com aumento da idade, elucidando uma perda na capacidade de crescimento da espécie e a necessidade de intervenções com manejo sustentável.

PALAVRAS-CHAVE: Manejo florestal, Floresta Ombrófila Mista, Crescimento.

\section{DENDROCHRONOLOGICAL ANALYSIS OF GROWTH OF Araucaria angustifolia IN PLATEAU MOUNTAINEER OF SANTA CATARINA}

\begin{abstract}
There is a concern with preserving the forest genotype of training with the presence of Araucaria angustifolia (Bertol.) Kuntze, it is necessary to acquire information, as data on growth, increment and age of trees, which can be used in sustainable management plans. The objective of this study was carried out dendrocronológico diagnosis of cumulative diameter growth for understanding the variability, with the intention of assisting in the management actions of the species. Therefore, from the analysis of growth rings, was used dendrochronological
\end{abstract}

information tree 133, addressed individually in natural fragments, located in São Joaquim. The results showed that these fragments, the species is increased in diameter between 0.20 and $1.42 \mathrm{~cm}$.ano-1, and ages ranging from 16 to over 100 years. The sites studied, is a gradual reduction in diameter growth with increasing age, elucidating a loss in species growth capacity and the need for interventions with sustainable management.

KEYWORDS: Forest management, Mixed rain forest, Growth. 


\section{INTRODUÇÃO}

No planalto serrano do Estado de Santa Catarina, ocorre a formação florestal Floresta Ombrófila Mista (FOM), caracterizada pela dominância da espécie Araucaria angustifolia (Bertol.) Kuntze.

A madeira da A.angustifolia já foi um dos principais produtos de exportação do país, oriunda de processos de exploração, realizados sem o planejamento de manejo florestal baseado nas diretrizes sustentáveis e sem a preocupação com a conservação e perpetuidade da espécie. Por essa razão, foi necessária a adotação de medidas radicais, que proibiram o manejo e o corte da araucária, interferindo de maneira negativa na economia das regiões onde a espécie ocorre e, sobretudo, na regeneração e desenvolvimento da mesma, bem como na continuidade e sucessão das florestas com araucária.

Os remanescentes florestais da FOM possuem a necessidade de preservação do seu genótipo florestal, tornando essencial a aquisição de informações que possam ser utilizadas em planos de manejo sustentável, assegurando a perpetuidade da espécie e a conservação dos remanescentes florestais. Assim, conhecer as taxas de crescimento e a produção de espécies florestais é de grande relevância para a manutenção dos fragmentos naturais, colaborando para a introdução do manejo florestal nessas áreas.

Com a necessidade de aquisição de dados sobre o crescimento, incremento e idade das árvores, a dendrocronologia apresenta-se como uma ferramenta eficaz, proporcionando uma aplicação direta no manejo florestal. Essa técnica consiste na análise e interpretação do crescimento anual dos anéis de crescimento das árvores, o que só é possível devido à sensibilidade das espécies arbóreas aos fatores ambientais e climáticos, tornando a dendrocronologia um dos métodos científicos mais utilizados para a aquisição desses dados (GONÇALVES, 2008). Portanto, por meio desta análise, são obtidos dados essenciais ao entendimento de fenômenos ecológicos e à estudos de longo prazo, a respeito da população de árvores, dinâmica e variabilidade ambiental.

Além de oferecer referências valiosas sobre a vida das árvores, as informações contidas nos anéis de crescimento têm sido importantes nas análises de eventos ecológicos e ambientais. Nesse contexto, a análise dos anéis de crescimento possibilita identificar e reconstruir as condições ambientais do passado, assim como a dinâmica das populações florestais (BOTOSSO \& MATTOS, 2002).

De acordo com Oliveira (2007), evidências dendrocronológicas demostram que a Araucaria angustifolia apresenta uma periodicidade de formação de anéis de crescimento anuais, sendo este um requisito essencial para a aplicação da dendrocronologia. Até o momento, diversos estudos dendrocronológicos estão sendo realizados, fazendo com que o conhecimento sobre a ecologia da espécie avance, através do inquérito sobre o desenvolvimento ao longo do tempo, comparando distintos fragmentos florestais e distintas condições de crescimento da espécie.

Assim, o objetivo deste estudo foi realizar um diagnóstico dendrocronológico do crescimento diamétrico acumulado de Araucária angustifolia para a compreensão da sua variabilidade, com a intenção de auxiliar nas ações de manejo da espécie.

\section{REVISÃO BIBLIOGRÁFICA}

A Floresta Ombrófila Mista, assim denominada por Veloso e Góes Filho (1982), é uma das mais importantes formações florestais do Brasil, tratando-se de um tipo de vegetação do Planalto Meridional, sendo um ecossistema do Bioma Mata Atlântica, característico da região sul do Brasil e 
de algumas áreas da região Sudeste. Segundo Veloso et al. (1991), sua principal característica é a presença predominante da Araucaria angustifolia (Bertol) O. Kuntz e, por esse motivo, a FOM também é conhecida como Floresta de Araucária ou Mata de Araucária.

As florestas de araucária, segundo Hueck (1972), já tiveram uma considerável importância para a economia florestal dos estados do sul do Brasil, tendo em vista que a madeira de Araucaria angustifolia chegou a representar $90 \%$ da exportação de madeira da região, por ser considerada leve e com boas características físicas e mecânicas, apresentando boa trabalhabilidade e facilidade de colagem (LORENZI, 1992; CARVALHO, 2002).

Assim, a madeira da araucária possibilita a geração de uma variedade de produtos, sendo utilizada na fabricação de celulose e papel, devido a características como a fibra longa. A tora da araucária também é utilizada para a fabricação de laminados, móveis, compensado, lápis, palitos, cabo de vassoura, assim como é indicada para construções em geral, construções rurais, entre outros (GUERRA et al.,2002).

Atualmente, qualquer atividade ligada ao corte e manejo da $A$. angustifolia está disciplinada pela Portaria Normativa DC $n \div 20$, que dispõe sobre o abate do pinheiro brasileiro e a colheita do pinhão, delimitando normas para que a atividade seja exercida (SILVA, 2006; BALBINOT et al., 2008). Essas medidas foram tomadas devido a inserção da espécie na lista de espécies vegetais brasileiras ameaçadas de extinção, em decorrência da exploração desmedida e sem nenhum tipo de planejamento sustentável.

Porém, em um ecossistema florestal, diversas mudanças acontecem a todo momento. Um dos principais eventos ocorrentes na floresta é a abertura de uma clareira, que pode ter como causa a morte de uma árvore, por exemplo. Quando isso acontece, há uma mudança na quantidade de luz, temperatura e umidade do solo, além de ocorrer um aumento no processo de decomposição e disponibilidade de nutrientes, favorecendo o surgimento de novas plântulas provenientes de um banco de sementes, até então dormentes, por não terem encontrado condições favoráveis à germinação. Além disso, estas condições fazem com que as plantas remanescentes sejam beneficiadas com um aumento no crescimento, sendo estas perturbações responsáveis pela sucessão florestal e dinâmica de produção da floresta (HIGUCHI et al., 2008).

De acordo com Souza e Soares (2013), as intervenções realizadas no manejo florestal buscam imitar os eventos que modificam a estrutura da floresta e que ocorrem naturalmente nos povoamentos, através de diferentes intensidades de corte. Deste modo, o manejo florestal conduzido de maneira correta pode colaborar para a dinâmica de crescimento e a sucessão de florestas nativas, evitando que a renovação da população seja prejudicada e, dessa forma, contribuindo para a conservação e perpetuidade das florestas.

O manejo florestal sustentado é uma alternativa para a exploração dos recursos florestais em florestas nativas pois visa o fornecimento contínuo dos produtos e serviços obtidos em florestas manejadas, priorizando o equilíbrio entre a colheita e a produção da floresta em longo prazo (SOUZA e SOARES, 2013).

Em várias partes do mundo, de acordo com Couto e Alves (2004), estão sendo implantados programas consistentes de manejo florestal sustentado, com o principal objetivo de proteger o setor florestal, favorecendo a exploração baseada em diretrizes sustentáveis.

Nesse sentido, quando há a intenção de realizar o manejo sustentado de uma floresta, é imprescindível que se tenha conhecimento sobre sua capacidade produtiva e seu potencial de crescimento, bem como outras características, que servirão como base na busca da perpetuidade da produção de produtos disponibilizados pela floresta, aliado à conservação dos ecossistemas (SOUZA et al., 2009). 
Com isso, faz-se necessário conhecer o crescimento da Araucaria angustifolia em suas regiões de ocorrência, sendo que, segundo Hess (2006), estudar o comportamento do crescimento particular para cada povoamento ou região permite reconhecer e analisar características distintas da floresta, possibilitando a determinação da capacidade produtiva do povoamento. Estas informações são úteis no desenvolvimento de ferramentas para tomada de decisão na intervenção sustentável nos povoamentos.

Para tanto, a dendrocronologia é uma ferramenta de resposta rápida que proporciona informações sobre incremento médio e estimativa de idade para espécies de regiões com sazonalidade definida. As pesquisas sobre a dinâmica das espécies através da dendrocronologia têm apresentado resultados relevantes, indicando a necessidade de reunir, definitivamente, esta técnica aos estudos que sirvam de apoio ao manejo florestal (MATTOS et al., 2011).

Essa metodologia consiste na leitura dos anéis de crescimento das árvores para a obtenção de informações sobre as mudanças que ocorreram na vida passada do indivíduo no que se refere a modificações em suas dimensões. A sensibilidade das espécies arbóreas em relação ao meio em que se encontram torna possível a utilização deste método. Portanto, fatores climáticos e ambientais fazem com que estas informações sejam registradas nos anéis de crescimento (GUTIÉRREZ et al., 2012; GONÇALVES, 2008).

Para Mattos et al. (2011), a dendrocronologia auxilia no estudo sobre a situação das florestas, possibilitando o acesso a importantes informações sobre o crescimento das árvores, além de fatores limitantes ou favoráveis ao crescimento, contribuindo para a compreensão da dinâmica da floresta.

\section{METODOLOGIA}

Os sítios amostrais considerados nesse estudo encontram-se no Planalto Serrano de Santa Catarina, no município de São Joaquim. Tratam-se de fragmentos remanescentes da Floresta Ombrófila Mista, com a presença natural da espécie Araucaria angustifolia.

Foram amostradas dois sítios, os quais possuem área total de 73,46 ha (São Joaquim 1), 19,72 ha (São Joaquim 2) e área amostral de 1,86 ha e 1,4 ha, respectivamente.

De acordo com a classificação de Köeppen, essa região apresenta clima cfb, isto é, temperado constantemente úmido e sem estação seca definida (Alvares et al., 2013). A altitude no município é de $1.352 \mathrm{~m}$, com temperatura média anual de $14^{\circ} \mathrm{C}$ e precipitação de $1.683 \mathrm{~mm}$. Os solos são classificados como Associação Neossolo Litólico + Cambissolos Hápicos + Neossolos Litólicos Eutróficos, relevo fortemente ondulado em fase pedregosa, campo e floresta subtropical (EMBRAPA, 2012).

$\mathrm{Na}$ aquisição dos dados utilizados na pesquisa, foram amostradas 133 árvores individuais com objetivo de cobrir as amplitudes de distribuição diamétrica da floresta. A fim de assegurar a representatividade da amostragem, foi calculada a suficiência amostral conforme equação em Sanquetta et al. (2014).

Para a análise dendrocronológica dos anéis de crescimento, utilizou-se da análise parcial de tronco, e desse modo, coletou-se de cada uma das 133 árvores suas variáveis dendrométricas e dois rolos de incremento perpendiculares entre si, tomados à altura do peito $(1,30 \mathrm{~m})$, utilizando o trado extrator de Pressler. As amostras foram acondicionadas em porta baguetas e, posteriormente em laboratório, foram fixadas com cola específica, tomando atenção quanto a orientação correta dos anéis de crescimento. Após a secagem em temperatura ambiente, os rolos de incremento foram polidos com lixas de diferentes granulometrias, no intuito de facilitar a visualização dos anéis. 
A medição do incremento e a contagem dos anéis de crescimento deu-se por meio da mesa de mensuração do aparelho Lintab 6, com precisão de 0,0001 mm, acoplada ao computador. Os dados obtidos nas medições foram registrados pelo programa Time Series Analysis Program - TSAP-Win. A datação cruzada dos anéis de crescimento foi realizada a partir da análise visual dos dados e gráficos gerados com o suprimento do programa Action integrado ao Excel 2014.

\section{RESULTADOS E DISCUSSÃO}

Na Tabela 1 são apresentados os valores mínimo, médio e máximo do incremento médio em diâmetro obtidos da análise dos anéis de crescimento para Araucaria angustifolia, nos sítios de São Joaquim.

Tabela 1: Desempenho do incremento médio em diâmetro para Araucaria angustifolia no planalto serrano de Santa Catarina.

\begin{tabular}{l|cc|cc}
\hline \multirow{2}{*}{} & \multicolumn{2}{c}{ São Joaquim 1 } & \multicolumn{2}{c}{ São Joaquim 2 } \\
\cline { 2 - 5 } & id & d cor. & id & d cor. \\
\hline Mínimo & 0,20 & 127,64 & 0,31 & 29,60 \\
Médio & 0,45 & 49,97 & 0,69 & 41,66 \\
Máximo & 0,72 & 50,29 & 1,42 & 35,01 \\
\hline
\end{tabular}

Em que: id: incremento em diâmetro (cm/ano), dcor.: diâmetro à altura do peito correspondente ao incremento diamétrico mínimo, máximo e médio em $(\mathrm{cm})$.

São Joaquim 1 apresentou incremento médio menor. Neste local encontram-se árvores com dimensões elevadas de diâmetro, as quais possuem média de idade de 51 anos, variando entre 16 e 78 anos, considerando aquelas em que foi possível a observação de todos os anéis de crescimento, até a medula.

O sítio 2 possui id médio, com valor maior em relação ao sítio 1 . Porém, com o recuo dos anéis de crescimento, pôde-se observar que as árvores de maior idade estão neste local, atingindo 96 anos nos casos em que foi possível chegar próximo à medula e, deste modo, possibilitando inferências corretas sobre a idade, incidindo em uma média de 68 anos.

No entanto, em alguns indivíduos presentes em ambos os sítios, não foi possível atingir os anéis mais próximos da medula, devido ao diâmetro elevado dos mesmos e, deste modo, infere-se que, entre as árvores amostradas, existem indivíduos com idade muito superior a 100 anos.

Dessa forma, os valores encontrados com a análise dos anéis mostram que existem árvores com idade bastante avançada, apresentando incremento em diâmetro próximo a estagnação. Por outro lado, observaram-se indivíduos mais jovens, de menor diâmetro, com taxas de incremento próximas às taxas das araucárias mais velhas. Esse comportamento pode ser explicado pela presença de competição imposta por parte dos exemplares mais velhos, impossibilitando que as demais árvores tenham acesso à recursos promotores do crescimento, como luminosidade, espaço e nutrientes, comprovando a hipótese da necessidade e possibilidade de intervenções de manejo florestal sustentável nessas áreas. 
As médias do id para São Joaquim são superiores às observadas por Minatti (2015), que encontrou um incremento médio de 0,34 cm.ano-1 nesse local, valor próximo aos mencionados nos trabalhos de Stepka (2012) e Durigan (1999) para a região.

O incremento anual acumulado em diâmetro está representado na Figura 1, estes são os valores medidos no rolo de incremento sem ajuste de modelo matemático. As figuras com os valores de incremento foram traçadas individualmente para cada sítio de estudo.
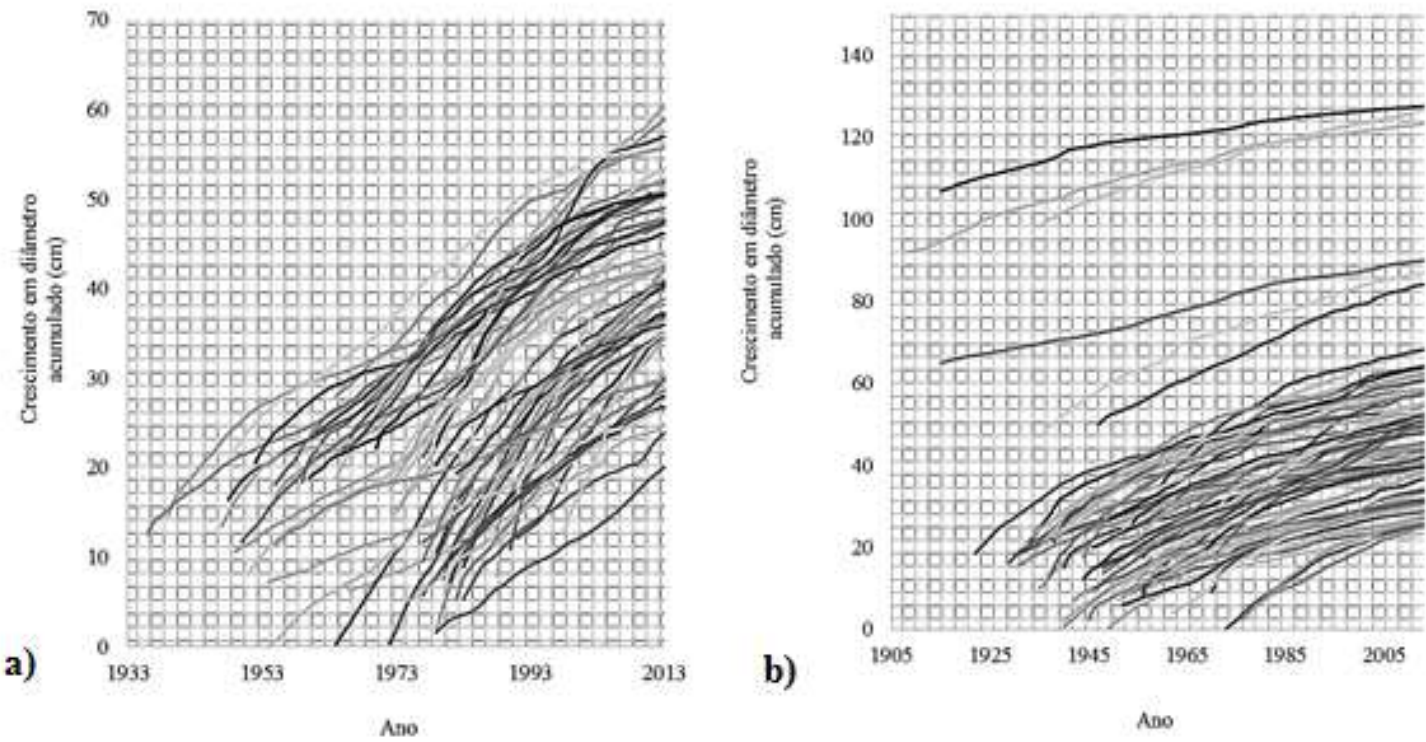

Figura 1: Representação do crescimento em d para araucária em: a) São Joaquim 1e b) São Joaquim 2.

No sítio de São Joaquim 1, observa-se a característica sigmoidal das curvas de crescimento, com o momento de inflexão do crescimento, indicando a capacidade de rápido desenvolvimento inicial da espécie e, após determinada idade, a estagnação da curva, representando que alguns indivíduos atingiram sua capacidade máxima de crescimento. Nesse sítio a idade média observada foi de 51 anos.

As árvores de maior idade encontram-se no sítio 2, com média de idade de 68 anos e, consequentemente, maiores valores de diâmetro à altura do peito. O rápido crescimento inicial das araucárias é novamente observado nas curvas de São Joaquim 2, principalmente nos indivíduos com diâmetro entre $20-30 \mathrm{~cm}$, não ocorrendo de forma tão acelerada nas demais árvores. Isso pode ter ocorrido devido à presença de fatores inibidores do crescimento dessas árvores. Observa-se claramente a estabilização das curvas de crescimento, principalmente nas que referem-se às árvores com diâmetro superior a $60 \mathrm{~cm}$, representado um crescimento quase nulo.

Os dados representados nessas curvas são referentes à árvores centenárias, pois foi possível análise retrospectiva dos anéis de crescimento, aproximadamente, até o ano de 1900. Percebe-se então que, há mais de 100 anos, estas árvores já haviam alcançado sua capacidade máxima de crescimento, confirmado pelas características estáveis que as curvas assumem. 
Para Mattos (2011), o crescimento em diâmetro é mais intenso quando a planta alcança os 20 a 30 anos. Após essa fase, o ritmo de crescimento vai cessando gradativamente, com o acontecimento da maturidade das árvores.

Assim, o crescimento de árvores vizinhas e, de certo modo, da floresta, pode estar sendo inibido e a regeneração natural da espécie sendo prejudicada. Essas relações e o comportamento das taxas de crescimento justificam a possibilidade de implantação de planos de manejo florestal sustentável nas matas de araucária, visando não só o aproveitamento da madeira dessa espécie, o que colabora com o desenvolvimento econômico da região, mas também garantindo a perpetuidade e a conservação desses remanescentes através do aumento das taxas de crescimento e estímulo da regeneração, tomando como base os preceitos do manejo florestal sustentável.

\section{CONCLUSÃO}

Com a análise dos anéis de crescimento ficou visível a capacidade de rápido crescimento inicial da espécie e uma estabilização do crescimento na idade de aproximadamente 40 anos.

Existe competição imposta pelos indivíduos das maiores classes diamétricas, reduzindo as taxas de crescimento das demais árvores.

A espécie possui grande potencial de crescimento e produção, todavia, são necessárias intervenções sustentáveis, através do manejo florestal, possibilitando uma perspectiva de retorno econômico, aliado à conservação e à recuperação da Araucaria angustifolia.

\section{REFERÊNCIAS BIBLIOGRÁFICAS}

ALVARES, C. A.; STAPE, J. L.; SENTELHAS, P. C.; GONÇALVES, J. L. M.; PAROVEK, G. (2013). Köppen's climate classification map for Brazil. Meteorologische Zeitschrift, 22. p. 711-728.

BALBINOT, R. et al. Tendências de consumo e preço de comercialização do pinhão (semente da Araucaria angustifolia (Bert.) O. Ktze.), no estado do Paraná. Guarapuava: Ambiência, v. 4, n. 3, 2008. p. 463-472,

BOTOSSO, C. P.; MATTOS, P. P. (2002). Conhecer a Idade das Árvores: Importância e Aplicação. Colombo: Embrapa Florestas (Embrapa Florestas. Documentos, 75). 25p.

COUTO, P. E.; ALVES, S. M. A. (2004). O manejo florestal no Brasil. SOBER. Disponível em: http://www.sober.org.br/palestra/12/080397.pdf. Acesso em 29 de abril de 2014.

CARVALHO, R. E. P. (2002). Pinheiro do Paraná. Colombo: EMBRAPA.

DURIGAN, M. E. (1999). Florística, dinâmica e análise protéica de uma Floresta Ombrófila Mista em São João do Triunfo - PR. 1999. 125f. Dissertação (Mestrado em Engenharia Florestal) Universidade Federal do Paraná, Curitiba.

EMBRAPA - Sistema brasileiro de classificação dos solos. Brasília, 2012. 
GONÇALVES, V. G. (2008). Dendrocronologia: Princípios teóricos, problemas práticos e aplicabilidade. - Universidade de Évora. Disponível em: http://old.www.cidehus.uevora.pt/textos/artigos/gerardo_dendocronolog ia.pdf. Acesso em: 4 de novembro de 2015.

GUERRA, M. P.; SILVEIRA, V.; REIS, M. S.; SCHNEIDER, L. (2002). Exploração, manejo e conservação da araucária (Araucária angustifólia). In: Sustentável mata atlântica: a exploração de seus recursos florestais. São Paulo: SENAC.

GUTIÉRREZ, E. et al. (2012). La história que nos explican los árboles. Disponívelem:<http://www.ub.edu/b_on/articulosCast/junio\%202012/dendrocronologiajunio-2012-cast.pdf>. Acesso em: 25 de abril de 2014.

HESS, A. F. (2006). Inter-relações no crescimento de Araucaria angustifolia (Bertol.) O. Kuntze em diferentes locais do Rio Grande do Sul. 178 f. Tese (Doutorado em Engenharia Florestal) Universidade Federal de Santa Maria, Santa Maria.

HIGUCH, N. et al. (2008). Noções básicas de manejo florestal. Grupo de pesquisas em manejo florestal/INPA. (Apostila). $270 \mathrm{p}$.

HUECK, K. (1972). As florestas da América do Sul. São Paulo: Polígono. 466 p.

LORENZI, H. (1992). Árvores brasileiras: manual de identificação e cultivo de plantas arbóreas nativas do Brasil, Nova Odessa: Plantarum, . v. 1, 352 p.

MATTOS, P. P. de; BRAZ, E. M.; HESS, A. F.; SALIS, S. M. de A. (2011). Dendrocronologia e o manejo florestal sustentável em florestas tropicais. (Embrapa Florestas. Documentos, 218); (Embrapa Pantanal. Documentos, 112). Colombo: Embrapa Florestas; Corumbá: Embrapa Pantanal. 37 p.

MINATTI, M. (2015). Dendrocronologia aplicada na geração de modelos de crescimento biométricos e ambientais para Araucaria angustifólia na fitorregião do Planalto Serrano, SC. Dissertação (Mestrado em Engenharia Florestal) Universidade do Estado de Santa Catarina, Lages.

OLIVEIRA,J. M. (2007). Anéis de crescimento de Araucaria angustifolia (Bertol.) O. Kuntze: Bases de dendroecologia em ecossistemas subtropicais montanos no Brasil. $139 \mathrm{f}$. Tese (Doutorado em Ecologia) - Universidade Federal do Rio Grande do Sul, Porto Alegre.

SANQUETTA, C. R. (2014). Fragmentação da Floresta Ombrófila Mista no Paraná. In: SANQUETTA, C. $R$ et al. Inventários Florestais: Planejamento e Execução - 3a. edição. 1. ed. Curitiba: Dos Autores, v. $1.406 \mathrm{p}$.

SILVA, C. V. (2006). Aspectos da obtenção e comercialização de pinhão na região de Caçador, SC. Florianópolis, 111f. Dissertação (Mestrado em Recursos Genéticos Vegetais).- Centro de Ciências Agrárias - Universidade Federal de Santa Catarina. Disponível em: http://<ww w.dominiopublico.gov.br/download/texto/cp001264.pdf>. Acesso em: 30 de março de 2014.

SOUZA, A. L. de; SOARES, C. P. B. (2013). Florestas Nativas: estrutura, dinâmica e manejo. Viçosa: UFV. 322 p. 
SOUZA, L. H. S.; FINGER, C. A. G.; SCHNEIDER, P. R. (2009, jul.-set). Incremento volumétrico de Nectandra megapotamica (Spreng.) Mez em Floresta Ombrófila Mista. Ciência Florestal, Santa Maria, 19 (3). p. 305-314.

STEPKA, T. F. (2012). Modelagem do crescimento e dendrocronologia em árvores nativas de Araucaria angustifolia, Cedrela fissilis e Ocotea porosa no sul do Brasil. 186 f. Tese (Doutorado em Engenharia Florestal) - Universidade Federal do Paraná, Curitiba.

VELOSO, H. P.; GÓES FILHO, L. (1982). Fitogeografia Brasileira: Classificação fisionômica-ecológica da vegetação neotropical. In: PROJETO RADAMBRASIL, Salvador. Bol. Técnico. Série vegetação.

VELOSO, H. P.; RANGEL FILHO; A. L. R.; LIMA, J. C. A. (1991). Classificação da Vegetação Brasileira, Adaptada a um Sistema Universal. Rio de Janeiro: IBGE, Departamento de Recursos Naturais e Estudos Ambientais. 124 p. 